Check for updates

Cite this: Chem. Sci., 2019, 10, 6565

๑ All publication charges for this article have been paid for by the Royal Society of Chemistry

\title{
Self-assembly of two robust 3D supramolecular organic frameworks from a geometrically non- planar molecule for high gas selectivity performance $\uparrow$
}

\author{
Yue Zhou, ${ }^{a}$ Liang Kan, ${ }^{a}$ Jarrod F. Eubank, ${ }^{b}$ Guanghua Li, ${ }^{a}$ Lirong Zhang ${ }^{a}$ \\ and Yunling Liu (iD)*a
}

The synthesis of highly porous frameworks has received continuous research interest, but achieving the ability to target stable and selective materials remains challenging. Herein, by utilizing a 'directionoriented' strategy and modulating reaction conditions, two novel 3D porous supramolecular organic framework (SOF) materials (JLU-SOF2 and JLU-SOF3, as isomers) are assembled from a non-planar building block (TMBTI = 2,4,6-trimethyl benzene-1,3,5-triyl-isophthalic acid) and they display permanent porosity, high thermal stability, and good recyclability. It is worth mentioning that the $\mathrm{CO}_{2}$ uptake values of JLU-SOF2 and JLU-SOF3 rank among the highest values for SOF-based materials under ambient conditions. Furthermore, these two materials exhibit preferential adsorption of $\mathrm{CO}_{2}$ over $\mathrm{N}_{2}$ and $\mathrm{CH}_{4}$, and can effectively separate the mixtures of light hydrocarbons. These studies indicate the possible application of JLU-SOF2 and JLU-SOF3 in trapping greenhouse gases and upgrading natural gas. In addition, this synthetic strategy introduces an effective method for developing remarkable 3D SOFs among other framework materials.

Received 18th January 2019
Accepted 27th May 2019

DOI: $10.1039 / c 9 s c 00290 a$

rsc.li/chemical-science

\section{Introduction}

Alleviating the escalation of concentration of atmospheric $\mathrm{CO}_{2}$ is an ongoing research topic. ${ }^{1-3}$ To solve this issue, adsorptionbased separation technology will likely be a feasible method until more effective technologies can be developed, which can realize the post-combustion carbon capture and purification of natural gas. ${ }^{3-5}$ For gas adsorbents, permanent porosity, sufficient void-space, high selectivity and good recyclability are crucial prerequisites for their use in practical applications. Over the past few decades, some novel porous framework materials, such as metal-organic frameworks (MOFs), ${ }^{6,7}$ covalent organic frameworks (COFs), ${ }^{8,9}$ and other crystalline porous materials, ${ }^{10-12}$ have been explored as potential adsorbents.

Supramolecular organic frameworks (SOFs, also called HOFs, abbreviation of hydrogen-bonded organic frameworks) constructed by hydrogen-bonding and $\pi-\pi$ interactions are

\footnotetext{
${ }^{a}$ State Key Laboratory of Inorganic Synthesis and Preparative Chemistry, College of Chemistry, Jilin University, Changchun 130012, P. R. China. E-mail: yunling@jlu. edu.cn; Fax: +86-431-85168624; Tel: +86-431-85168614

${ }^{b}$ Florida Southern College, 111 Lake Hollingsworth Dr, Lakeland, FL, USA 33801

$\dagger$ Electronic supplementary information (ESI) available: Synthesis procedures of TMBTI, structure descriptions, materials characterization, and crystal data for JLU-SOF2 and JLU-SOF3. CCDC 1842179 and 1861545. For ESI and crystallographic data in CIF or other electronic format see DOI: 10.1039/c9sc00290a
}

attractive gas adsorbents thanks mainly to their low framework density and regeneration by simple recrystallization..$^{10,13-19}$ However, the stability of SOFs is still a challenge although a number of SOFs with permanent porosity have been reported. ${ }^{20-35}$ Considering their highly predictable hydrogenbonding motif, some (carboxylic acid)-containing organic units were selected to construct SOF materials by the groups of Zentner, Moorthy, Hisaki and others. ${ }^{24,36-41}$ The vast majority of these SOFs are $2 \mathrm{D}$ materials due to the limited propagation ability of planar blocks. Thus, synthesis of new building blocks with a non-planar configuration, that is, utilizing a 'directionoriented' strategy, may be an effective method to construct 3D SOF materials. Li et al. reported the first solution-phase 3D periodic SOF in water, and they pointed out that by utilizing self-assembly of tetrahedral building blocks and cucurbit[8]uril ordered 3D frameworks could be achieved..$^{42}$ Pillarene-based 3D SOF materials were constructed by Yang and co-workers, and their construction is mainly attributed to the spatial configuration and abundant electron donor-acceptor components of macrocyclic molecules. ${ }^{43}$ For organic small-molecules, modifying the central component of the planar organic entity to make it rotate or replacing it with a flexible group ${ }^{38}$ is a feasible way to break the planarity of building blocks. On the basis of the above considerations, a non-planar organic building block, 2,4,6-trimethyl benzene-1,3,5-triyl-isophthalic acid (TMBTI), is synthesized by modifying the central phenyl ring of 
$3,3^{\prime}, 3^{\prime \prime}, 5,5^{\prime}, 5^{\prime \prime}$-benzene-1,3,5-triyl-hexabenzoic acid $\left(\mathrm{H}_{6} \mathrm{BHB}\right)^{44}$ with methyl groups (Scheme 1). In terms of the 'directionoriented' strategy, desired 3D frameworks would be assembled from TMBTI because it inherently exhibits a high propensity to form multiple hydrogen bonds in different directions (i.e., beyond two dimensions).

Due to the tremendous freedom of hydrogen bonds, the selfassembly of the same constituent could also allow for achievement of different SOFs based on diverse hydrogen-bonding modes. ${ }^{24,45-49}$ To the best of our knowledge, though some SOF materials have been reported to have hydrogen-bonded isomers, most of these polymorphs were formed simultaneously under the same conditions. ${ }^{24,47}$ Therefore, design strategies, including precise modulation of reaction conditions, are vitally important to yield unique or desired structures as phase-pure materials.

Herein, as an experimental proof-of-concept, two 3D SOF isomers, JLU-SOF2 and JLU-SOF3, with high thermal stability and permanent microporous nature are assembled by subtly modulating reaction conditions. It is notable that some MOFs have been synthesized using the TMBTI ligand, but all of them are isomorphous. ${ }^{50-52} \mathbf{J L U}-\mathbf{S O F 2}$ and JLU-SOF3 exhibit excellent $\mathrm{CO}_{2}$ capture and separation ability, which surpasses that of the majority of SOF materials. Besides, these two materials show salient performance for purification of natural gas under ambient conditions.

\section{Results and discussion}

\section{Structure descriptions}

Single-crystal X-ray diffraction (SCXRD) analysis reveals that JLUSOF2 and JLU-SOF3 crystallize in the trigonal $P \overline{3} 1 c$ and hexagonal $P \overline{6} 2 c$ space group, respectively. As illustrated in Fig. 1a and b, each TMBTI block existing in both of them is connected with six other organic units through six pairs of intermolecular $-\mathrm{COOH} \cdots$ HOOC- hydrogen bonds. As expected, these two SOFs exhibit 3D hydrogen-bonded structures, which are mainly attributed to the propagation ability of the geometrically non-planar block in different directions. JLU-SOF3 is assembled by the classic carboxylic acid dimer motif exclusively, and the $\mathrm{O}-\mathrm{H} \cdots \mathrm{O}$ distances are 2.605(2), 2.615(7), 2.630(6), and 2.628(3) ̊̊ (Table S3†). Meanwhile, two types of hydrogen-bonding motifs are present in JLUSOF2: one is the typical carboxylic acid dimer formed between two

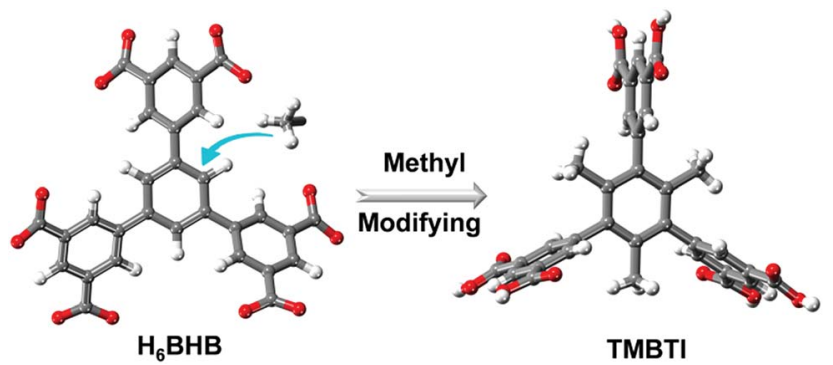

Scheme 1 Synthesis of the non-planar TMBTI block by modifying $\mathrm{H}_{6} \mathrm{BHB}$ with methyl groups.
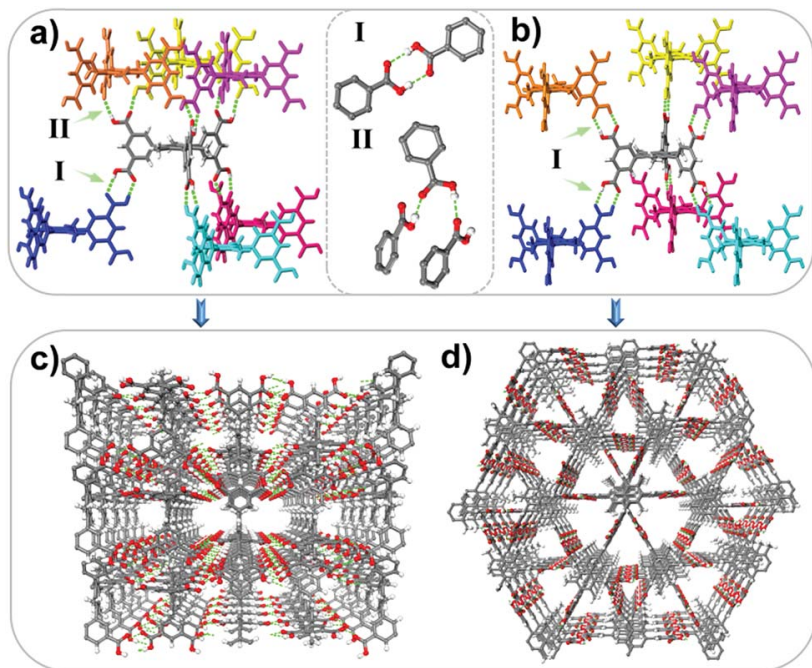

Fig. 1 Hydrogen-bonding interactions of JLU-SOF2 and JLU-SOF3 and their different intermolecular $-\mathrm{COOH} \cdots \mathrm{HOOC}$ - hydrogenbonding motifs ( $a$ and $b$ ); ball-and-stick models of JLU-SOF2 and JLUSOF3 along the $x$-axis and $z$-axis, respectively ( $c$ and $d$ ).

carboxyl groups and the distance of $\mathrm{O}(4)-\mathrm{H}(4) \cdots \mathrm{O}(3) \# 4$ is 2.642(2) $\AA$; but the other is an uncommon motif formed among three carboxyl groups and the distance of $\mathrm{O}(2)-\mathrm{H}(2) \cdots \mathrm{O}(1) \# 3$ is 2.6606(19) ^ (Table S4†). The different hydrogen-bonding interactions and corresponding packing modes of TMBTI in JLU-SOF2 and JLU-SOF3 were caused by the differences in reaction systems in terms of solvent polarity, solubility and temperature. Nevertheless, these two SOFs display similar pore sizes. JLU-SOF2 contains homogeneous open channels with window sizes of about $5.6 \AA \times 3.8 \AA$ along the $x$-axis and $y$-axis, respectively, considering the van der Waals radius (Fig. 1c and S3†). For JLU-SOF3, two types of triangular cavities ( $5.8 \AA$ and $3.2 \AA$ in diameter) co-exist in the framework along the $z$-axis (Fig. $1 \mathrm{~d}$ and $\mathrm{S} 5 \dagger$ ). Interestingly, the whole structure of JLU-SOF3 contains three equivalent interwoven frameworks which are linked by $\mathrm{C}-\mathrm{H} \cdots \pi$ interactions, as supported by the measured distance of $3.39 \AA$ A between the $\mathrm{H}$ atoms and the centroids of phenyl rings of the isophthalic acid groups (Fig. 3d, S6 and S7 $†$ ). There exist typical honeycomb channels in a single net with an internal dimension of about $19.3 \AA$ along the $z$-axis, considering the van der Waals radius (Fig. $3 \mathrm{~b}$ and $\mathrm{S} 8{ }^{\dagger}$ ). However, it is expected that the stability of JLU-SOF3 will be significantly increased after three-fold interpenetration.

In the crystal structure of JLU-SOF2, the central phenyl ring could be described as a 3-connected node, and the isophthalic acid group could be simplified as a 4-connected node (by three hydrogen bonds) (Fig. 2 and S4†). Consequently, the structure of JLU-SOF2 can be rationalized as a new $(3,4)$-connected network with a point symbol of $\left\{6^{3}\right\}\left\{6^{5} \times 10\right\}^{3}$, which possesses four types of tiles $\left[6^{5}\right],\left[10^{3}\right],\left[6^{2} \times 10^{2}\right]$ and $\left[6^{3} \times 10^{3}\right]$. Similarly, the single net of JLU-SOF3 can be reduced into a $(3,3)$-connected etc net topology with an $\left\{8^{3}\right\}$ point symbol, and the total framework consists of three-fold interpenetrated networks (Fig. 3 and S9†). The potential solvent-accessible volume of JLU-SOF2 and JLUSOF3 is $43.7 \%$ and $51.3 \%$, respectively, estimated using PLATON after removal of disordered 1,4-dioxane (DOA) solvent. 


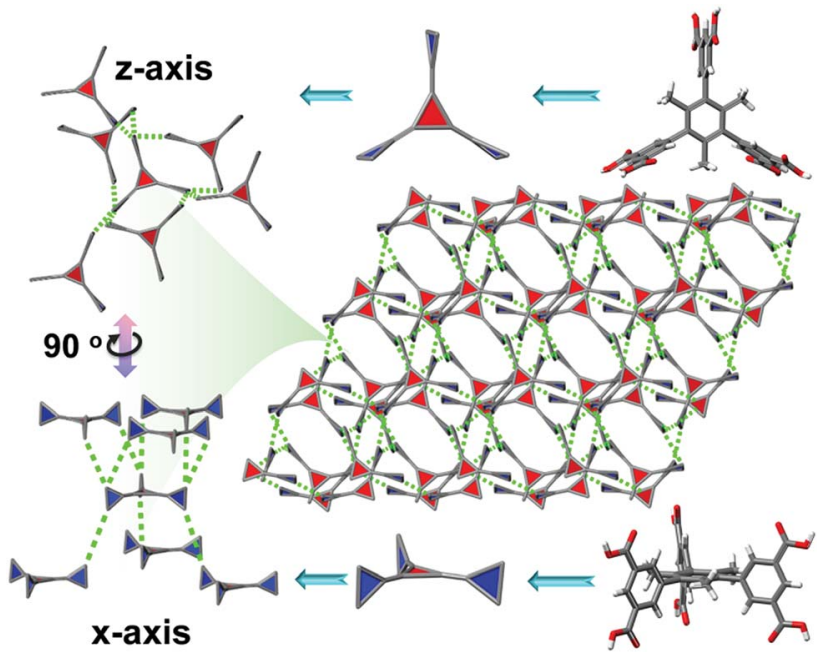

Fig. 2 Schematic representation of the $(3,4)$-connected net of JLUSOF2 showing the simplified organic building block and hydrogen bonds along the $x$-axis and $z$-axis.
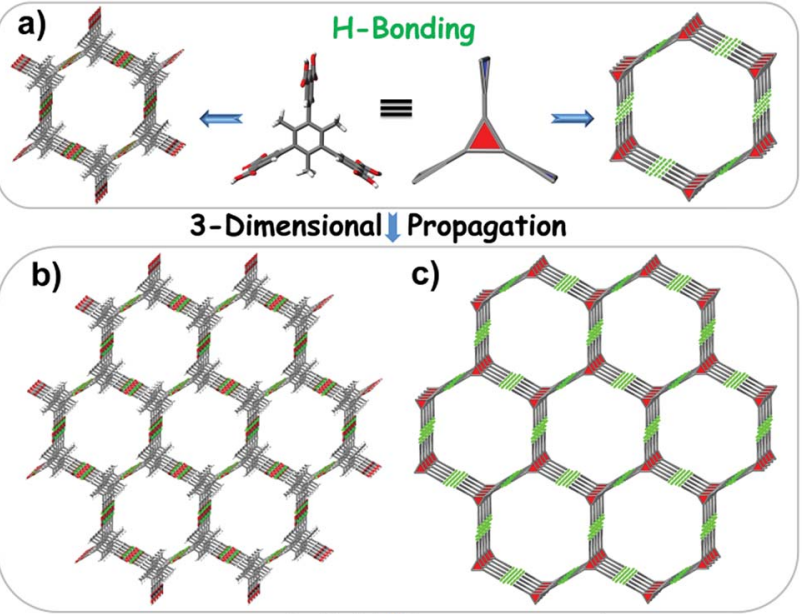

3-Fold \Interpenetration

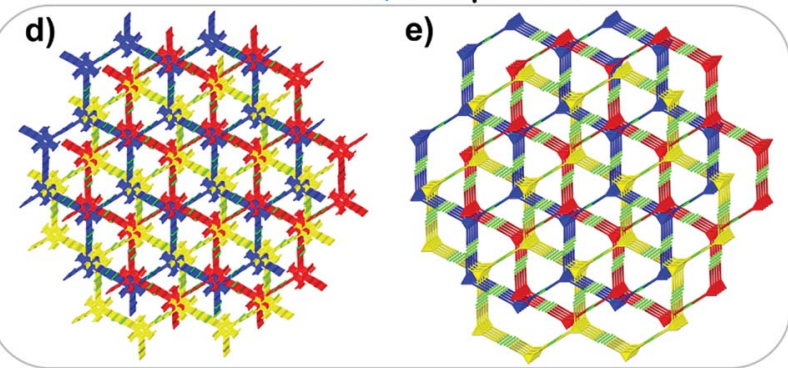

Fig. 3 Stick and schematic representation of JLU-SOF3 showing the simplified building block and hydrogen bonds for a single channel (a), single net ( $b$ and $c$ ) and three-fold interpenetrated nets ( $d$ and e) along the $z$-axis.

\section{Stability studies}

Thermogravimetric analyses (TGA) reveal that all solvent is removed at about $230{ }^{\circ} \mathrm{C}$ with a weight loss of $23 \%$ for JLU-SOF2, followed by a relatively steady plateau until $420{ }^{\circ} \mathrm{C}$, after that the material begins to decompose (Fig. S10†). JLU-SOF3 exhibits a weight loss of $24 \%$ before $210{ }^{\circ} \mathrm{C}$, which corresponds to the loss of guest molecules, and then the material begins to decompose at $430{ }^{\circ} \mathrm{C}$. The crystalline phase purity of assynthesized JLU-SOF2 and JLU-SOF3 was identified from the consistency between the measured powder X-ray diffraction (PXRD) pattern and the simulated one from the SCXRD data (Fig. 4 and S12a†). To investigate their permanent porosity, $\mathrm{N}_{2}$ sorption isotherms of these two compounds were studied. The isotherms exhibit a sharp rise in uptake at the low $P / P_{0}$ region corresponding to the natural behavior of microporous materials (Fig. S13†). Brunauer-Emmett-Teller surface areas of JLU-SOF2 and JLU-SOF3 are calculated to be 937 and $1141 \mathrm{~m}^{2} \mathrm{~g}^{-1}$, respectively, which are higher than those of most SOF-based materials $^{16,53-55}$ (Tables S5 and S6 $\dagger$ ). The experimental pore volumes of JLU-SOF2 and JLU-SOF3 $\left(0.47\right.$ and $\left.0.63 \mathrm{~cm}^{3} \mathrm{~g}^{-1}\right)$ are consistent with the theoretical values $\left(0.47\right.$ and $0.63 \mathrm{~cm}^{3} \mathrm{~g}^{-1}$, the detailed calculation method is provided in the ESI $\dagger$ ) estimated from the crystal structures, demonstrating that the cavities of the frameworks have been activated adequately.

In view of practical applications, the reusability and stability of these materials were explored. The $\mathrm{N}_{2}$ sorption was tested for the used materials that were placed in air for one week after adsorption (named JLU-SOF2R and JLU-SOF3R). The BET surface areas are 884 and $1005 \mathrm{~m}^{2} \mathrm{~g}^{-1}$ for JLU-SOF2R and JLUSOF3R, which are slightly lower than those of the pristine samples (Fig. S13 and Table S7 $\dagger$ ). It indicates that the reused materials remain intact basically. Variable-temperature PXRD and corresponding $\mathrm{N}_{2}$ sorption were performed to test their thermal stability. As shown in Fig. 4 and $\mathrm{S} 11, \dagger$ the primary peaks are consistent with those of as-synthesized JLU-SOF2, and some changes can be observed, especially for the $350{ }^{\circ} \mathrm{C}$ treated sample. The $\mathrm{N}_{2}$ uptake of JLU-SOF2 did not decreased significantly below $250{ }^{\circ} \mathrm{C}$ (Fig. S14 and Table S8广). Increasing the temperature above $300{ }^{\circ} \mathrm{C}$ lowered the BET surface area and a noticeable up-tail emerged at high $P / P_{0}$. Yet, the $\mathrm{N}_{2}$ isotherms

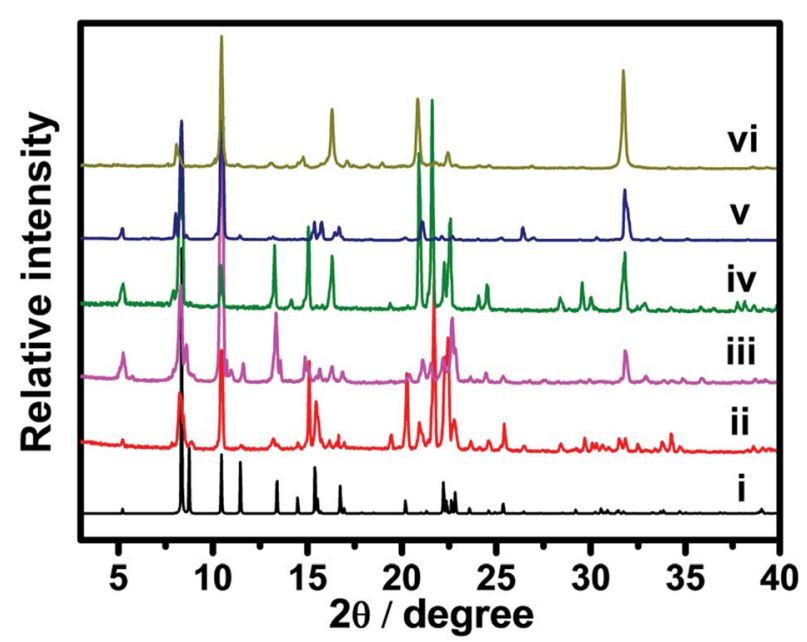

Fig. 4 PXRD patterns of simulated (i), as-synthesized (ii), exchanged in $\mathrm{CH}_{3} \mathrm{CN}$ for one week (iii), regenerated after recrystallization of dissolved SOFs (iv), after $\mathrm{CO}_{2}$ adsorption (v), and heated under $350{ }^{\circ} \mathrm{C}$ for 2 hours (vi) for JLU-SOF2. 
preserved their type-I shape. These observations may be caused by the cleaving of hydrogen bonds and stacking of the samples. ${ }^{35}$ These results indicate that the crystallinity and porosity of JLU-SOF2 remain stable up to $250{ }^{\circ} \mathrm{C}$, and are preserved partially up to $350^{\circ} \mathrm{C}$. Similar are made for JLU-SOF3 (Fig. S12, S15 and Table S9†). The up-tail phenomenon was analysed in detail based on the pore volumes and scanning electron microscopy (SEM) images of these materials (Fig. S16, Tables S8 and S9, $\uparrow$ the detailed analysis is provided in the ESI $\dagger$ ). The ${ }^{1} \mathrm{H}$ NMR spectra and solubility of these materials indicate that the TMBTI blocks remained intact the samples treated at $350{ }^{\circ} \mathrm{C}$ (Fig. S17 and S18, $\dagger$ detailed information is presented in the ESI $\dagger$ ). The high thermal stability of these two SOFs can be attributed to the strong and multiple hydrogen-bonding interactions. In addition, the $\mathrm{CH}_{3} \mathrm{CN}$-exchanged and regenerated samples still exhibit good crystallinity.

\section{Gas adsorption and separation}

The high pore volume and permanent porosity of these two materials inspired us to probe into their potential for application as gas adsorbents. Both JLU-SOF2 and JLU-SOF3 exhibit stepwise $\mathrm{CO}_{2}$ adsorption at $195 \mathrm{~K}$ with a slight hysteresis loop, and the uptake values are 13.75 and $15.18 \mathrm{mmol} \mathrm{g}^{-1}$, respectively (Fig. 5a). Furthermore, JLU-SOF2 and JLU-SOF3 also display notable $\mathrm{CO}_{2}$ adsorption amounts at higher temperatures with 4.25 and $4.49 \mathrm{mmol} \mathrm{g}^{-1}$ at $273 \mathrm{~K}$, and 1.98 and $2.34 \mathrm{mmol} \mathrm{g}^{-1}$ at $298 \mathrm{~K}$, respectively (Fig. 5b). It is worth mentioning that the $\mathrm{CO}_{2}$ uptake values of JLU-SOF3 rank
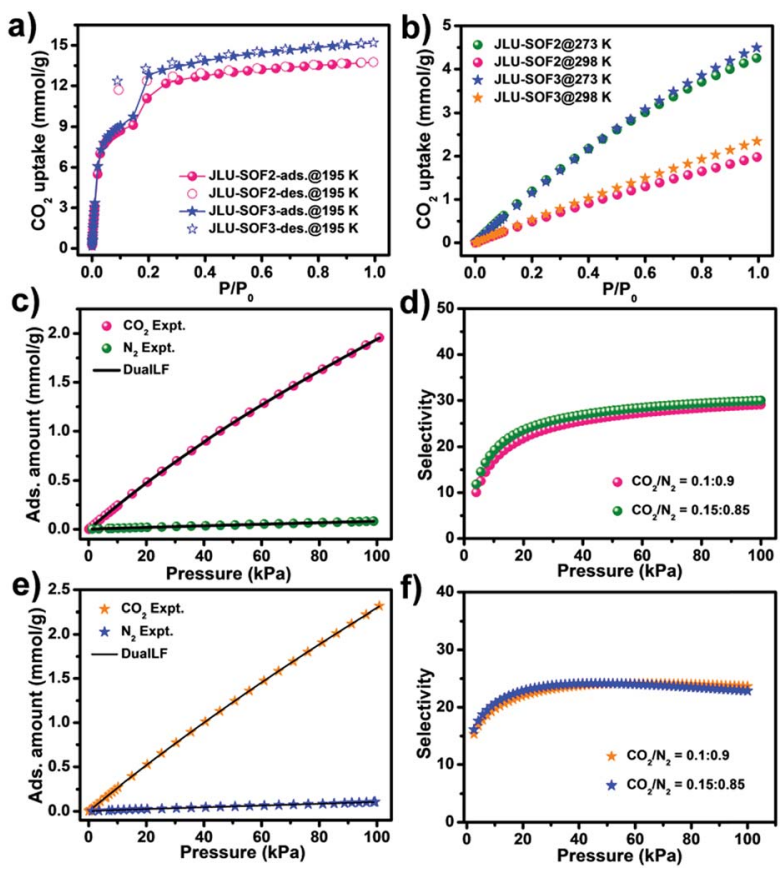

Fig. $5 \mathrm{CO}_{2}$ adsorption isotherms at $195 \mathrm{~K}(\mathrm{a})$ and at 273 and $298 \mathrm{~K}$ (b) for JLU-SOF2 and JLU-SOF3; $\mathrm{CO}_{2}$ and $\mathrm{N}_{2}$ adsorption isotherms at 298 $\mathrm{K}$ under 1 bar along with the DSLF fits ( $c$ and e) and the adsorption selectivity of the binary mixtures predicted using IAST ( $d$ and f) for JLUSOF2 and JLU-SOF3. among the values of activated carbon, ${ }^{56}$ ZIF-100, ${ }^{57}$ JLU-MOF50 (ref. 58) and the highest values for SOFs except for HOF-5a ${ }^{15}$ and IISERP-HOF1 (ref. 38) (Tables S10 and S11†). In contrast to the high $\mathrm{CO}_{2}$ uptake values, much less $\mathrm{N}_{2}$ is adsorbed, 0.24 and $0.36 \mathrm{mmol} \mathrm{g}^{-1}$ at $273 \mathrm{~K}$, and these values are decreased to 0.11 and $0.14 \mathrm{mmol} \mathrm{g}^{-1}$ at $298 \mathrm{~K}$, respectively (Fig. S20†). These observed differential adsorption behaviors between $\mathrm{CO}_{2}$ and $\mathrm{N}_{2}$ for JLU-SOF2 and JLU-SOF3 imply that these materials are probably potential separators for capture of $\mathrm{CO}_{2}$ from flue-gas.

To predict their separation ability for $\mathrm{CO}_{2} / \mathrm{N}_{2}$, ideal adsorbed solution theory (IAST) was used to calculate the selectivity for the binary mixtures based on single-component adsorption data fitting using the dual-site Langmuir-Freundlich (DSLF) equation at $298 \mathrm{~K}$. As expected, the selectivity of JLU-SOF2 was calculated to be 30.0 and 29.1, respectively, for the binary mixtures of $\mathrm{CO}_{2} / \mathrm{N}_{2}$ (v/v: $15 / 85$ and 10/90) at $298 \mathrm{~K}$ and 1 bar and the values are 22.8 and 23.6 for JLU-SOF3 under the same conditions (Fig. 5c-f). Encouragingly, these values are higher than those of considerable SOF materials, and exceed those of MOF materials such as PCN-88, ${ }^{3}$ UiO-67, ${ }^{59}$ and NU-1000 (ref. 60) (Table S12 $\dagger$ ). The highly selective adsorption of $\mathrm{CO}_{2}$ over $\mathrm{N}_{2}$ may be explained by the following aspects: (1) the kinetic diameter of $\mathrm{CO}_{2}(3.3 \AA)$ is smaller than that of $\mathrm{N}_{2}(3.64 \AA)$; (2) the attractive and unique interactions formed by the quadrupole moment of $\mathrm{CO}_{2}$ will increase the adsorption ability; and (3) the host cavities containing carboxyl groups exhibit stronger affinity behavior for $\mathrm{CO}_{2}$ than for $\mathrm{N}_{2}$, which can be identified using the isosteric adsorption enthalpy $\left(Q_{\mathrm{st}}\right)$. As shown in Fig. S21 and S22, $\uparrow$ the $Q_{\text {st }}$ of $\mathrm{CO}_{2}$ and $\mathrm{N}_{2}$ are 24.5 and $12.1 \mathrm{~kJ} \mathrm{~mol}^{-1}$ for JLU-SOF2, and 21.8 and $17.0 \mathrm{~kJ} \mathrm{~mol}^{-1}$ for JLU-SOF3 at zero coverage, respectively, as calculated from the adsorption data at 273 and $298 \mathrm{~K}$.

Another particularly salient feature of JLU-SOF2 and JLUSOF3 is the adsorption and separation ability for light hydrocarbons under ambient conditions. Single-component gas sorption isotherms measured at $298 \mathrm{~K}$ under 1 bar show that the adsorption amounts of $\mathrm{CH}_{4}$ for JLU-SOF2 and JLU-SOF3 are 0.96 and $1.05 \mathrm{mmol} \mathrm{g}^{-1}$, those for $\mathrm{C}_{2} \mathrm{H}_{6}$ are 4.04 and $4.41 \mathrm{mmol} \mathrm{g}^{-1}$, and those for $\mathrm{C}_{3} \mathrm{H}_{8}$ are 4.11 and $4.70 \mathrm{mmol} \mathrm{g}{ }^{-1}$, respectively (Fig. 6a-c). Following a temperature decrease to $273 \mathrm{~K}$, the maximum adsorption amounts are increased to 1.67 and $1.73 \mathrm{mmol} \mathrm{g}^{-1}$ for $\mathrm{CH}_{4}, 5.10$ and $5.79 \mathrm{mmol} \mathrm{g}^{-1}$ for $\mathrm{C}_{2} \mathrm{H}_{6}$, and 4.55 and $5.51 \mathrm{mmol} \mathrm{g}^{-1}$ for $\mathrm{C}_{3} \mathrm{H}_{8}$. The used materials exhibit a similar adsorption capacity for these gases to the pristine samples (Fig. S23 and Table S7 $\dagger$ ). The selectivity of JLU-SOF2 for equimolar binary mixtures of $\mathrm{C}_{2} \mathrm{H}_{6} / \mathrm{CH}_{4}$ and $\mathrm{C}_{3} \mathrm{H}_{8} / \mathrm{CH}_{4}$ is 16.3 and 48.1 at $298 \mathrm{~K}$ and $1 \mathrm{bar}$, respectively (Fig. S24†). There are two primary reasons for the different adsorption ability and high selectivity: (1) the strength of mutual gas interaction decreases as the molecular size decreases; ${ }^{61}$ and (2) the hydrocarbon-building block dispersion interaction is higher for larger and more polarizable molecules, ${ }^{\mathbf{6 2 , 6 3}}$ which can be proved from the gas affinity towards JLU-SOF2 in the order of $\mathrm{C}_{3} \mathrm{H}_{8}>$ $\mathrm{C}_{2} \mathrm{H}_{6}>\mathrm{CH}_{4}$ according to the $Q_{\text {st }}$ of $43.8,32.3$ and $16.6 \mathrm{~kJ} \mathrm{~mol}^{-1}$ at zero coverage, respectively (Fig. 6d). With respect to JLUSOF3, the selectivity for $\mathrm{C}_{2} \mathrm{H}_{6} / \mathrm{CH}_{4}$ and $\mathrm{C}_{3} \mathrm{H}_{8} / \mathrm{CH}_{4}$ is 17.8 and 89.2, respectively (Fig. 6e and f). Similarly, the gas affinity of JLU-SOF3 shows a consistent trend for $\mathrm{C}_{3} \mathrm{H}_{8}, \mathrm{C}_{2} \mathrm{H}_{6}$, and $\mathrm{CH}_{4}$ and 

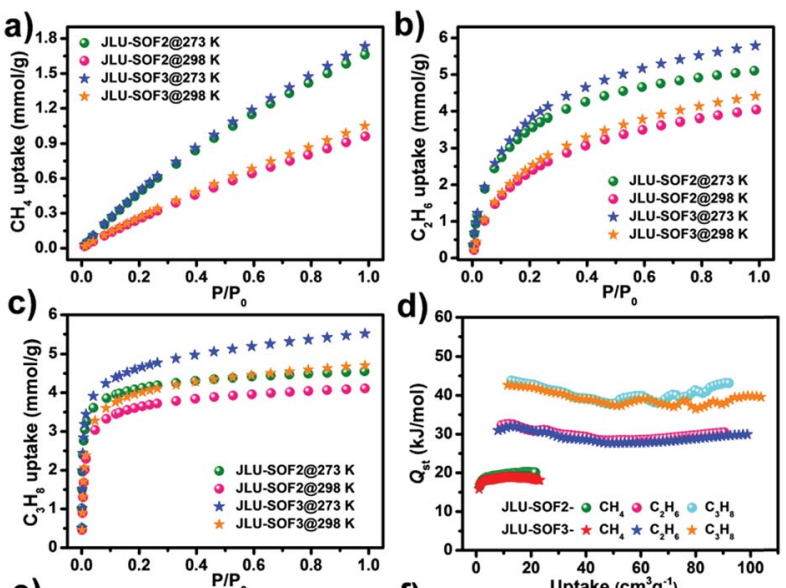

e)
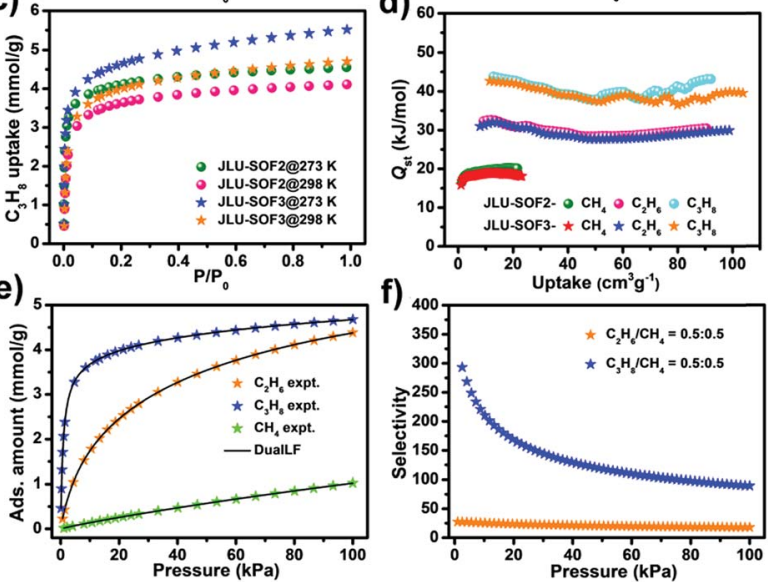

Fig. $6 \mathrm{CH}_{4}(\mathrm{a}), \mathrm{C}_{2} \mathrm{H}_{6}$ (b), and $\mathrm{C}_{3} \mathrm{H}_{8}$ (c) adsorption isotherms at 273 and $298 \mathrm{~K}$ as well as the corresponding $Q_{\text {st }}$ (d) for JLU-SOF2 and JLUSOF3; $\mathrm{CH}_{4}, \mathrm{C}_{2} \mathrm{H}_{6}$, and $\mathrm{C}_{3} \mathrm{H}_{8}$ adsorption isotherms at $298 \mathrm{~K}$ under $1 \mathrm{bar}$ along with DSLF fits (e) and the adsorption selectivity for equimolar binary mixtures of $\mathrm{C}_{2} \mathrm{H}_{6} / \mathrm{CH}_{4}$ and $\mathrm{C}_{3} \mathrm{H}_{8} / \mathrm{CH}_{4}$ (f) for JLU-SOF3.

the $Q_{\text {st }}$ is $42.7,31.0$, and 15.8 , respectively. These results imply that the suitable pore sizes of these two SOFs induce stronger host-guest interactions with larger hydrocarbons than with the smaller ones. It should be mentioned that only one SOF material, HOF-TCPB, has been reported to separate light hydrocarbons significantly, and the article mainly focuses on the separation of $\mathrm{CH}_{4}$ from $\mathrm{C}_{4}$ hydrocarbons. ${ }^{64}$ In addition to this separation, the selectivity of our materials for $\mathrm{CO}_{2} / \mathrm{CH}_{4}$ mixtures (v/v: 50/50 and 5/95) was explored, and the values of which are 2.2 and 2.1 for JLU-SOF2 and 2.3 and 2.2 for JLU-SOF3 at $298 \mathrm{~K}$ and 1 bar, respectively (Fig. S25 $\dagger$ ). The above studies indicate the high potential for application of these two materials in selective capturing of light hydrocarbons and upgrading of natural gas.

\section{Conclusions}

In summary, by utilizing a 'direction-oriented' strategy and selectively modulating reaction conditions, two 3D SOF materials were synthesized based on different hydrogen-bonding modes from a singular pre-designed non-planar building block. JLU-SOF2 and JLU-SOF3 exhibit permanent porosity, high thermal stability, and good recyclability. It is worth mentioning that these two SOF materials display favourable $\mathrm{CO}_{2}$ adsorption capacity at ambient temperature. More importantly, these two materials show preferential adsorption of $\mathrm{CO}_{2}$ over $\mathrm{N}_{2}$, as well as $\mathrm{CO}_{2}, \mathrm{C}_{2} \mathrm{H}_{6}$ and $\mathrm{C}_{3} \mathrm{H}_{8}$ over $\mathrm{CH}_{4}$. These substantial results indicate that JLU-SOF2 and JLU-SOF3 could serve as effective reservoirs and separators for greenhouse gas trapping and natural gas upgrading. Notably, the successful crystallization of these two materials offers a feasible method to fabricate 3D SOFs, and in principle, this strategy is not limited to the construction of SOF materials, but suitable for other porous framework materials also.

\section{Experimental}

\section{Materials and methods}

The chemicals were purchased from commercial sources and used without further purification. The Fourier transform infrared (FT-IR) spectrum was recorded on a Bruker IFS-66v/S FT-IR spectrometer from 400 to $4000 \mathrm{~cm}^{-1}$ using $\mathrm{KBr}$ pellets. TGA analyses were performed on a TGA Q500 thermogravimetric analyzer with a heating rate of $10{ }^{\circ} \mathrm{C} \min ^{-1}$ under an air atmosphere. Elemental analyses were completed on a vario MICRO elemental analyzer. PXRD patterns were collected on a Rigaku D/max-2550 diffractometer $\left(\mathrm{Cu}-\mathrm{K}_{\alpha}\right.$ radiation, $\lambda=$ $1.5418 \AA$ A). Nuclear magnetic resonance (NMR) spectra were obtained using a Varian $300 \mathrm{MHz}$ NMR analyzer. The SEM images were measured using a HITACHI SU-8010.

\section{Synthesis of TMBTI}

The TMBTI building block was synthesized by Suzuki-Miyaura reaction according to the literature with some adjustments, ${ }^{\mathbf{5 0}}$ and the detailed information is given in the ESI. $\dagger$

\section{Preparation of JLU-SOF2}

TMBTI (6 mg) dissolved in DOA (1 mL) was sealed in a vial, and then heated at $85{ }^{\circ} \mathrm{C}$ for 2 days. Colorless hexagonal prismshaped crystals, JLU-SOF2, were obtained and dried in air with a yield of $75 \%$. Elemental analysis (\%) calcd for JLU-SOF2 $\left(\mathrm{C}_{33} \mathrm{H}_{24} \mathrm{O}_{12} \cdot 2 \mathrm{C}_{4} \mathrm{H}_{8} \mathrm{O}_{2}, \mathrm{TMBTI} \cdot 2 \mathrm{DOA}\right)$ : $\mathrm{C} 62.43$, $\mathrm{H}$ 5.11; found: $\mathrm{C}$ $60.13, \mathrm{H} 4.99$.

\section{Preparation of JLU-SOF3}

TMBTI (6 mg) was dissolved in DOA $(1 \mathrm{~mL})$, and then acetonitrile was slowly diffused into the solution at room temperature for 1 day. The colorless hexagonal rod-like crystals, JLU-SOF3, were collected and air-dried with a yield of $72 \%$. Elemental analysis (\%) calcd for JLU-SOF3 $\left(\mathrm{C}_{33} \mathrm{H}_{24} \mathrm{O}_{12} \cdot 2 \mathrm{C}_{4} \mathrm{H}_{8} \mathrm{O}_{2}\right.$, TMBTI-2DOA): C 62.43, H 5.11; found: C 60.11, H 4.88.

\section{Regeneration of JLU-SOF2 and JLU-SOF3}

The prepared JLU-SOF2 (or JLU-SOF3) was dissolved in ethanol by ultrasonication, and then the solution was evaporated in a rotary evaporator to give the TMBTI building block. The regeneration procedures were the same as the original preparation of JLU-SOF2 (or JLU-SOF3).

\section{X-ray crystallography}

Crystallographic data of as-synthesized JLU-SOF2 and JLU-SOF3 were acquired on a Bruker Apex II CCD diffractometer using graphite-monochromated $\mathrm{Mo}_{\alpha} \mathrm{K}_{\alpha}$ radiation $(\lambda=0.71073 \AA)$ at 
$293 \mathrm{~K}$ and at $153 \mathrm{~K}$, respectively. The structures of these two SOFs were resolved by a direct method and refined by fullmatrix least-squares on $F^{2}$ using the SHELXTL program. ${ }^{65}$ The non-hydrogen atoms were refined with anisotropic displacement parameters and the hydrogen atoms were located geometrically with isotropic parameters. In addition, the "SQUEEZE" command was utilized because of the significantly disordered solvent molecules in the pores. Topological analysis was carried out using TOPOS 4.0. ${ }^{66}$ The final formulae of the structures were derived from the crystallographic data, TGA and elemental analyses data. The summarized crystallographic data and all the hydrogen-bonds data are presented in Tables S2S4. $\uparrow$ The supplementary crystallographic data for JLU-SOF2 and JLU-SOF3 (CCDC numbers: 1842179 and 1861545†) can be achieved free of charge from the Cambridge Crystallographic Data Centre upon request at www.ccdc.cam.ac.uk/data_request/ cif.

\section{Gas adsorption measurements}

Before gas adsorption measurements, JLU-SOF2 and JLU-SOF3 were exchanged with acetonitrile 8 times for 2 days to fully remove the guest molecules, DOA, which can be identified by TGA analyses. Then, the exchanged samples were activated by using the 'outgas' function of the surface area analyzer at $100{ }^{\circ} \mathrm{C}$ for $10 \mathrm{~h}$. Surface areas were calculated using $\mathrm{N}_{2}$ adsorption isotherms at $77 \mathrm{~K}$ obtained using a Micromeritics ASAP 2040 instrument. $\mathrm{CO}_{2}$ adsorption isotherms measured at $195 \mathrm{~K}$ were acquired on a Micromeritics ASAP 2020 instrument. $\mathrm{CO}_{2}, \mathrm{CH}_{4}$, $\mathrm{C}_{2} \mathrm{H}_{6}, \mathrm{C}_{3} \mathrm{H}_{8}$, and $\mathrm{N}_{2}$ adsorption isotherms were collected on a Micromeritics 3-Flex and a Micromeritics ASAP 2020 PLUS HD88 instrument at 273 and $298 \mathrm{~K}$.

\section{Conflicts of interest}

There are no conflicts to declare.

\section{Acknowledgements}

The authors gratefully acknowledge the financial support of the National Natural Science Foundation of China (No. 21771078, 21671074, and 21621001), the 111 Project (B17020), the National Key Research and Development Program of China (2016YFB0701100). We thank Dr Libo Sun, Mr Xiaodong Sun, Mr Jiantang Li and Mr Jiaming Gu from Jilin University for their assistance in the synthesis of TMBTI and helpful discussions. We also thank Dr Kui-Zhan Shao from Northeast Normal University for his kind technical support relating to the crystallographic data.

\section{Notes and references}

1 D. W. Keith, Science, 2009, 325, 1654.

2 D. M. D'Alessandro, B. Smit and J. R. Long, Angew. Chem., Int. Ed., 2010, 49, 6058.

3 J.-R. Li, J. Yu, W. Lu, L.-B. Sun, J. Sculley, P. B. Balbuena and H.-C. Zhou, Nat. Commun., 2013, 4, 1538.
4 K. Sumida, D. L. Rogow, J. A. Mason, T. M. McDonald, E. D. Bloch, Z. R. Herm, T.-H. Bae and J. R. Long, Chem. Rev., 2012, 112, 724.

5 J.-R. Li, R. J. Kuppler and H.-C. Zhou, Chem. Soc. Rev., 2009, 38, 1477.

6 K. Adil, Y. Belmabkhout, R. S. Pillai, A. Cadiau, P. M. Bhatt, A. H. Assen, G. Maurinb and M. Eddaoudi, Chem. Soc. Rev., 2017, 46, 3402.

7 T. L. Easun, F. Moreau, Y. Yan, S. Yang and M. Schröder, Chem. Soc. Rev., 2017, 46, 239.

8 A. P. Côte, A. I. Benin, N. W. Ockwig, M. O'Keeffe, A. J. Matzger and O. M. Yaghi, Science, 2005, 310, 1166.

9 S. Das, P. Heasman, T. Ben and S. Qiu, Chem. Rev., 2017, 117, 1515.

10 J. Lü and R. Cao, Angew. Chem., Int. Ed., 2016, 55, 9474.

11 B. Wang, A. P. Côté, H. Furukawa, M. O'Keeffe and O. M. Yaghi, Nature, 2008, 453, 207.

12 Y. Zhu, H. Long and W. Zhang, Chem. Mater., 2013, 25, 1630. 13 Z.-T. Li, Beilstein J. Org. Chem., 2015, 11, 2057.

14 Y.-F. Han, Y.-X. Yuan and H.-B. Wang, Molecules, 2017, 22, 266.

15 H. Wang, B. Li, H. Wu, T.-L. Hu, Z. Yao, W. Zhou, S. Xiang and B. Chen, J. Am. Chem. Soc., 2015, 137, 9963.

16 J. Lü, C. Perez-Krap, M. Suyetin, N. H. Alsmail, Y. Yan, S. Yang, W. Lewis, E. Bichoutskaia, C. C. Tang, A. J. Blake, R. Cao and M. Schröder, J. Am. Chem. Soc., 2014, 136, 12828.

17 Y. Zhou, B. Liu, X. Sun, J. Li, G. Li, Q. Huo and Y. Liu, Cryst. Growth Des., 2017, 17, 6653.

18 A. Chaix, G. Mouchaham, A. Shkurenko, P. Hoang, B. Moosa, P. M. Bhatt, K. Adil, K. N. Salama, M. Eddaoudi and N. M. Khashab, J. Am. Chem. Soc., 2018, 140, 14571.

19 Y.-H. Luo, X.-T. He, D.-L. Hong, C. Chen, F.-H. Chen, J. Jiao, L.-H. Zhai, L.-H. Guo and B.-W. Sun, Adv. Funct. Mater., 2018, 28, 1804822.

20 W. Yang, A. Greenaway, X. Lin, R. Matsuda, A. J. Blake, C. Wilson, W. Lewis, P. Hubberstey, S. Kitagawa, N. R. Champness and M. Schröder, J. Am. Chem. Soc., 2010, 132, 14457.

21 T.-H. Chen, I. Popov, W. Kaveevivitchai, Y.-C. Chuang, Y.-S. Chen, O. Daugulis, A. J. Jacobson and O. Š. Miljanić, Nat. Commun., 2014, 5, 5131.

22 X.-Z. Luo, X.-J. Jia, J.-H. Deng, J.-L. Zhong, H.-J. Liu, K.-J. Wang and D.-C. Zhong, J. Am. Chem. Soc., 2013, 135, 11684.

23 M. Mastalerz and I. M. Oppel, Angew. Chem., Int. Ed., 2012, 51, 5252.

24 C. A. Zentner, H. W. H. Lai, J. T. Greenfield, R. A. Wiscons, M. Zeller, C. F. Campana, O. Talu, S. A. FitzGerald and J. L. C. Rowsell, Chem. Commun., 2015, 51, 11642.

25 P. Li, Y. He, Y. Zhao, L. Weng, H. Wang, R. Krishna, H. Wu, W. Zhou, M. O'Keeffe, Y. Han and B. Chen, Angew. Chem., Int. Ed., 2015, 54, 574.

26 R. S. Patil, D. Banerjee, C. Zhang, P. K. Thallapally and J. L. Atwood, Angew. Chem., Int. Ed., 2016, 55, 4523.

27 W. Yan, X. Yu, T. Yan, D. Wu, E. Ning, Y. Qi, Y. F. Han and Q. Li, Chem. Commun., 2017, 53, 3677. 
28 T. Yu, D. Ou, Z. Yang, Q. Huang, Z. Mao, J. Chen, Y. Zhang, S. Liu, J. Xu, M. R. Bryce and Z. Chi, Chem. Sci., 2017, 8, 1163. 29 D.-D. Zhou, Y.-T. Xu, R.-B. Lin, Z.-W. Mo, W.-X. Zhang and J.-P. Zhang, Chem. Commun., 2016, 52, 4991.

30 M. Morshedi, M. Thomas, A. Tarzia, C. J. Doonan and N. G. White, Chem. Sci., 2017, 8, 3019.

31 A. Karmakar, R. Illathvalappil, B. Anothumakkool, A. Sen, P. Samanta, A. V. Desai, S. Kurungot and S. K. Ghosh, Angew. Chem., Int. Ed., 2016, 55, 10667.

32 J. Lü, C. Perez-Krap, F. Trousselet, Y. Yan, N. H. Alsmail, B. Karadeniz, N. M. Jacques, W. Lewis, A. J. Blake, F.-X. Coudert, R. Cao and M. Schröder, Cryst. Growth Des., 2018, 18, 2555.

33 D. F. Sava, V. Ch. Kravtsov, J. Eckert, J. F. Eubank, F. Nouar and M. Eddaoudi, J. Am. Chem. Soc., 2009, 131, 10394.

34 I. Hisaki, Y. Suzuki, E. Gomez, B. Cohen, N. Tohnai and A. Douhal, Angew. Chem., Int. Ed., 2018, 57, 12650.

35 Q. Yin, P. Zhao, R.-J. Sa, G.-C. Chen, J. Lü, T.-F. Liu and R. Cao, Angew. Chem., Int. Ed., 2018, 57, 7691.

36 A. Bajpai, P. Venugopalan and J. N. Moorthy, Cryst. Growth Des., 2013, 13, 4721.

37 H. W. H. Lai, R. A. Wiscons, C. A. Zentner, M. Zeller and J. L. C. Rowsell, Cryst. Growth Des., 2016, 16, 821.

38 S. Nandi, D. Chakraborty and R. Vaidhyanathan, Chem. Commun., 2016, 52, 7249.

39 I. Hisaki, S. Nakagawa, N. Ikenaka, Y. Imamura, M. Katouda, M. Tashiro, H. Tsuchida, T. Ogoshi, H. Sato, N. Tohnai and M. Miyata, J. Am. Chem. Soc., 2016, 138, 6617.

40 I. Hisaki, S. Nakagawa, N. Tohnai and M. Miyata, Angew. Chem., Int. Ed., 2015, 54, 3008.

41 I. Hisaki, H. Toda, H. Sato, N. Tohnai and H. Sakurai, Angew. Chem., Int. Ed., 2017, 56, 15294.

42 J. Tian, T.-Y. Zhou, S.-C. Zhang, S. Aloni, M. V. Altoe, S.-H. Xie, H. Wang, D.-W. Zhang, X. Zhao, Y. Liu and Z.-T. Li, Nat. Commun., 2014, 5, 5574.

43 L.-L. Tan, H. Li, Y. Tao, S. X.-A. Zhang, B. Wang and Y.-W. Yang, Adv. Mater., 2014, 26, 7027.

44 Z. Guo, H. Wu, G. Srinivas, Y. Zhou, S. Xiang, Z. Chen, Y. Yang, W. Zhou, M. O'Keeffe and B. Chen, Angew. Chem., Int. Ed., 2011, 50, 3178.

45 H. Yamagishi, H. Sato, A. Hori, Y. Sato, R. Matsuda, K. Kato and T. Aida, Science, 2018, 361, 1242.

46 Y. Li, M. Handke, Y.-S. Chen, A. G. Shtukenberg, C. T. Hu and M. D. Ward, J. Am. Chem. Soc., 2018, 140, 12915.
47 I. Hisaki, N. Ikenaka, S. Tsuzuki and N. Tohnai, Mater. Chem. Front., 2018, 2, 338.

48 P. Li, O. Alduhaish, H. D. Arman, H. Wang, K. Alfooty and B. Chen, Cryst. Growth Des., 2014, 14, 3634.

49 H. Wang, Z. Bao, H. Wu, R.-B. Lin, W. Zhou, T.-L. Hu, B. Li, J. C.-G. Zhao and B. Chen, Chem. Commun., 2017, 53, 11150.

50 X. Zhao, X. Wang, S. Wang, J. Dou, P. Cui, Z. Chen, D. Sun, X. Wang and D. Sun, Cryst. Growth Des., 2012, 12, 2736.

51 L. Li, S. Tang, X. Lv, M. Jiang, C. Wang and X. Zhao, New J. Chem., 2013, 37, 3662.

52 J. Yang, X. Wang, F. Dai, L. Zhang, R. Wang and D. Sun, Inorg. Chem., 2014, 53, 10649.

53 Y. He, S. Xiang and B. Chen, J. Am. Chem. Soc., 2011, 133, 14570.

54 W. Yang, B. Li, H. Wang, O. Alduhaish, K. Alfooty, M. A. Zayed, P. Li, H. D. Arman and B. Chen, Cryst. Growth Des., 2015, 15, 2000.

55 H. Wang, H. Wu, J. Kan, G. Chang, Z. Yao, B. Li, W. Zhou, S. Xiang, J. C.-G. Zhao and B. Chen, J. Mater. Chem. A, 2017, 5, 8292.

56 D. P. Bezerra, R. S. Oliveira, R. S. Vieira, C. L. Cavalcante and D. C. Azevedo, Adsorption, 2011, 17, 235.

57 B. Wang, A. P. Côté, H. Furukawa, M. O'Keeffe and O. M. Yaghi, Nature, 2008, 453, 207.

58 X. Sun, S. Yao, C. Yu, G. Li, C. Liu, Q. Huo and Y. Liu, J. Mater. Chem. A, 2018, 6, 6363.

59 B. Wang, H. Huang, X.-L. Lv, Y. Xie, M. Li and J.-R. Li, Inorg. Chem., 2014, 53, 9254.

60 P. Deria, S. Li, H. Zhang, R. Q. Snurr, J. T. Hupp and O. K. Farha, Chem. Commun., 2015, 51, 12478.

61 H. Kim, J. Park and Y. Jung, Phys. Chem. Chem. Phys., 2013, 15, 19644.

62 J. Li, X. Luo, N. Zhao, L. Zhang, Q. Huo and Y. Liu, Inorg. Chem., 2017, 56, 4141.

63 Y. He, W. Zhou, R. Krishna and B. Chen, Chem. Commun., 2012, 48, 11813.

64 F. Hu, C. Liu, M. Wu, J. Pang, F. Jiang, D. Yuan and M. Hong, Angew. Chem., Int. Ed., 2017, 56, 2101.

65 G. M. Sheldrick, SHELXTL-NT, version 5.1, Bruker AXS Inc., Madison, WI, 1997.

66 V. A. Blatov, A. P. Shevchenko and D. M. Proserpio, Cryst. Growth Des., 2014, 14, 3576. 